\title{
A Arte dos Irmãos Quay à luz do Grande Vidro: a Narrativa
}

The art of the Quay Brothers in the light of The Large Glass: the Tale

EITHNE O'NEILL

Escritora e crítica de cinema, França

FÁBIO FONSECA (TRADUTOR)

Universidade Federal de Uberlândia (UFU) Uberlândia, Brasil

\section{RESUMO}

A refinada arte cênica dos irmãos Quay, sendo ela em stop-motion ou ao vivo, é notoriamente misteriosa. Evitando os códigos do cinema narrativo, seu mundo imaginário, em grande parte feito à mão, resiste às tentativas de ser definido de maneira unívoca. Após um olhar mais atento, constata-se que o mundo dos irmãos Quay revela elementos formais presentes nas estratégias adotadas por Duchamp na realização do seu trabalho inacabado - $O$ Grande Vidro. Em que medida é que estas obras de arte, cinéticas ou estáticas, têm uma história para contar? Esta questão, tendo como método a análise comparativa, pode ajudar a esclarecer o que é uma narrativa.

\section{PALAVRAS-CHAVE}

Stop-motion, o inacabado, poeira, desejo.

\begin{abstract}
A B S T R A C T
Both stop-motion and live, the elaborate scenic art of the Quay Brothers is notoriously mysterious. Eschewing the codes of narrative cinema, their largely hand crafted imaginary world defies clear-cut definitions. On closer inspection, it is seen to share formal components with the strategies of Duchamp's unfinished conceptual structure Large Glass. To what extent may it be said that these enigmatic arte-facts, cinematic or static, tell a story? As a comparative method of enquiry, the question may help to shed light on the telling of tales as such.
\end{abstract}

\section{KE Y WORDS}

Stop-motion, the unfinished, dust, desire. 
These things never happen but are always. ${ }^{1}$

\section{Introdução}

Nascidos na Filadélfia em 1947, os gêmeos Quay se especializaram em animação em volume chamada stop motion. Graduados pelo Philadelphia College of Art, continuaram seus estudos no Royal College of Art de Londres, cidade onde residem desde 1970. Em 1980, eles fundaram o Studios Koninck com Keith Griffiths como produtor. Ao longo de quarenta anos, eles dirigiram trinta curtas-metragens com um viés fantástico. A esse corpus se somam os longas-metragens filmados ao vivo, inspirados nos romances, Institute Benjamenta (1995), em preto e branco, e The Piano Tuner of Earthquakes (2005), em cores e associando bonecos a atores.

Os filmes anunciam o tema milenar da bela mulher amada, condenada ou morta. Desde o primeiro curta-metragem dos Quay, Nocturna Artificialia (1979), a música tem sido uma constante neste mundo inquietante. Em 2000, Karlheinz Stockhausen compôs uma partitura para In Absentia, evocação de Emma Hauck (1878-1920), uma paciente diagnosticada esquizofrênica que escreve incansavelmente para o marido. A arte dos Quay é de uma beleza hipnótica, realçada por um humor irônico. Marionetes, alfinetes, penugem de cardo, garfos, elásticos, um macaco e humanos coabitam e se deixam. Trilhas sonoras marcantes pontuam esses filmes poéticos, às vezes comparáveis a recitais de ópera.

Também são numerosas as encomendas para esses ilustradores de formação. Eles desenham capas de obras como o estudo sobre Andreï Tarkovski, de Mark Le Fanu, ou Le Château des destins croisés, de Italo Calvino, uma série de contos mágicos. Entre seus documentários está The Phantom Museum (Channel 4 TV, 2003), sobre a Collection Sir Henry Wellcome de artefatos anatômicos. Suas cenografias de teatro, de ópera e de balé, para O Amor das Três Laranjas de Prokofiev, La Puce à l'Oreille de Feydeau e Le Bourgeois gentilhomme de Molière confirmam sua conexão com a literatura assim como com as artes do espetáculo.

\section{Histórias de origem}

Atraídos pela narrativa fantástica, os Quay se voltam para a Europa Central e a América Latina. De Street of Crocodiles (1986) surge o clima pesado do antigo Império AustroHúngaro descrito na narrativa de origem homônima (1934) do polonês Bruno Schulz. O Institute Benjamenta transpõe Jakob von Gunten (1909), conto de feitiçaria de Robert Walser, escritor da Suíça de língua alemã (1878-1956). Jakob, o protagonista, se matricula em uma escola decadente para mordomos, onde aprende a arte de não esperar nada da vida. Publicado em 1940, La invención de Morel, fábula de antecipação do argentino Adolfo Bioy Casares, é o começo de The Piano Tuner of Earthquakes. Na véspera de seu casamento com Adolfo, uma futura noiva, Malvina Van Stille é morta por um cientista louco, Doutor Droz; ele a sequestra em uma ilha, declarando: "Logo você

1 Em inglês, a tradução de Arthur Nock, propõe para a Seção IV, dedicada aos mitos: "All this did not happen at any one time but always is so: the mind sees the whole process at once, words tell of part first, part second", Salluste, Traité des Dieux et du Monde, Cambridge University Press, pagina 9. 
cantará para mim, na minha cama pela eternidade”. Nos Quay, a influência se perfila por Raymond Roussel, romancista e dramaturgo, autor das narrativas, Impressions d'Afrique, sobre náufragos em um país fabuloso (1910), e Locus Solus, nome de uma propriedade marcada por prisioneiros em celas de vidro e maquinas refinadas (1914).

Na época do lançamento do Institute Benjamenta, os Quay explicam: O que se passa na sombra, nas zonas cinzentas também nos interessa, tudo o que é evasivo e fugidio, tudo o que se pode dizer em belos semi-tons ou na sombra profunda (ROSE, 2004). Esse gosto pelo efêmero e o incompatível se manifesta na fantasia de um décimo terceiro mês concebido por Schulz, uma bandeira sob a qual os Quay gostam de criar. Rejeitando rótulos, eles aceitam o epíteto de "surrealista" para a imagética dos mundos atemporais que chamam "sonhos" 2. Sua empatia pelas histórias de Roussel os aproxima de Marcel Duchamp, dadaísta e amigo dos surrealistas.

Nascido em 1887, Duchamp pertence à mesma geração de quatro escritores importantes cujas narrativas inspiram os Quay, Roussel (1887-1933), Walser (1878-1956), Schulz (1892-1942) e Franz Kafka (1883-1924). Uma experiência de fim de século instaurando um desejo de renovação reúne esses espíritos. A afinidade dos Quay com essa constelação de gênios reflete sua inclinação não-conformista. Da mesma forma, seu distanciamento dos códigos estabelecidos na sétima arte, animação e vida, se aparenta à rejeição histórica pelo artista Duchamp da pintura descritiva, chamada retiniana. Como Duchamp, os Quay se comprazem com o papel do acaso na criatividade artística.

A experimentação duchampiana com a arte conceitual culmina em o Grande Vidro, exposto durante a Grande Guerra em 1915. Hoje na coleção permanente do Museu de Arte da Filadélfia, este "quadro hilariante", como Duchamp o descreveu (SANOUILLET, 1975, p.45), propõe uma variante modernista de um tropos consagrado da cultura ocidental, o da noiva. O esboço de Duchamp da "noiva”, essa "divorciada da expressão pictórica convencional” (ibid., p.181), parece ter entre seus ancestrais a figura futurística que aparece no início de Locus Solus: “Leve de aparência, embora inteiramente metálica, a jovem estava suspensa em um pequeno balão amarelo claro... embaixo, o chão era forrado da mais estranha maneira" (ROUSSEL, 1965, p.32). É uma silhueta prototípica da parte de sua noiva batizada por Duchamp "A mulher suspensa". Ele confirma: "É Roussel que, fundamentalmente, foi responsável pelo meu Vidro".

O solteiro mói seu próprio chocolate: na parte inferior do Grande Vidro, um imponente cilindro giratório, chamado Triturador de Chocolate, simboliza o onanismo automático. Emblema da mecanização do fenômeno amoroso, e único desenho executado segundo as leis da perspectiva, a máquina com manivela sublinha o isolamento respectivo da "noiva" e dos seus pretendentes. Quebrado acidentalmente em 1916 e depois remontado, o Grande Vidro é declarado em 1923 “definitivamente inacabado". Frágil, o artefato suscita por seu estado incompleto uma repercussão raramente atribuída a obras de arte realizadas para seu fim consagrado. 0 advento Quay significa uma tentativa inocente de retomar "este plano de máquina amorosa" (LABEL, 1985, p.145)?

2 Retrato dos Irmãos Quay. Frames, le webzine de l'animation et du cinéma. Disponível em: http://frames.free. $\mathrm{fr} / 1 /$ quay.htm. Acesso em: 07/02/2021. 


\section{Paralelos artísticos}

Uma similaridade de procedimento liga o arauto dos ready-mades e os Irmãos, conhecedores da história da arte. Corda, bola de pingue-pongue, cabide, bússola, chifre de veado, chumaço de algodão, poeira e tantos objetos encontrados servem aos animadores para confeccionar seus espaços imaginários. Na esfera dos Irmãos, o suporte do Vidro está presente via profusão de janelas manchadas e espelhos embaçados, vitrines sujas, olhos de conta craquelados em suas bonecas à Hans Bellmer, a ótica de uma câmera, a vidraça suja separando um teatro de autômatos do afinador Felisberto.

Como suporte essencial, o vidro reforça as semelhanças entre os artistas. Embora transparentes, os painéis do Grande Vidro erguem uma barreira suplementar entre essa narrativa de amor cortada pela raiz e o espectador. Por sua vez, os Quay são adeptos da autorreflexão. Fiel ao seu título, Nocturna Artificialia, estritamente falando, seu primeiro filme, atrai a atenção para o artifício cinético: a mão do operador põe o Cinetoscópio anacrônico em movimento. The Cabinet of Jan Svankmajer (1984), uma homenagem ao animador tcheco, começa com a fabricação da cabeça do mestre do stop-motion. Um cuspo de saliva desencadeia a máquina do filme Street of Crocodiles.

\section{Poeira, fios, vidro}

Nada é lixo para os Quay; seu objetivo é: "criar um mundo visto através de um vidro sujo" (Habib, 2002). A imagem da $13^{a}$ epístola pauliniana do Novo Testamento surge: "Vemos agora por meio de um espelho, de maneira obscura”. Não há dúvida, a metáfora abrange o Grande Vidro feito à mão, com sua opacidade, seus desenhos enigmáticos, suas rachaduras e sua poeira encrustada. Nos dois ateliês sucessivos de Duchamp em Nova York, a poeira acumulada sobre uma placa de vidro ao longo dos anos foi fotografada por Man Ray em 1920. Emoldurada, essa poeira se torna o artefato nomeado "Dust breeding”. Graças à forma em -ing, o grupo nominal do título inglês da fotografia, mais naturalista do que o título francês "Élevage de poussièrre", abarca uma dimensão expressiva de uma vitalidade ativa. A poeira possui uma potência geradora.

Além disso, "ver através de um vidro sujo" ecoa o título do segundo volume escrito por Lewis Carroll sobre as aventuras surreais de Alice, Through the Looking Glass (Alice através do espelho, 1872). Alice personifica em sua própria pessoa a miniaturização característica dos personagens do stop-motion Quay. Mesmo que ela seja uma miniatura, Alice é uma personalidade notável. Não há dúvida de que o espectador entra em um filme dos Quay como Alice que atravessa o espelho dizendo "curioser and curioser" (mais e mais curiosa); da mesma forma, o espectador do Grande Vidro esfrega os olhos: o que esse objeto quer dizer? Por fim, a aversão Quay para um efeito liso e limpo se estende até a trilha sonora. Eles apreciam a textura não "muito própria ou polida" das gravações de seu compositor, o polonês Lech Jankowski, que conhecem em 1982. Durante as filmagens de Street of Crocodiles, os Irmãos evitam dissipar o que está no chão: a poeira volátil.

Duchamp "desenha" usando as cores e silhuetas do Grande Vidro por meio de óleo e fios de chumbo. A estes respondem, mutatis mutandis, os fios de marionetes Quay. Street of Crocodiles mostra que o fio guiando o homem marionete é cortado no momento em que ele 
perambula por um labirinto de becos. Ele será em seguida preso em uma armadilha de uma bachelor machine, contam os Irmãos. O fio visível que segura e solta o perambulador seria ele também o emblema do fio da trama? Uma série de elementos reúne os Irmãos enigmáticos e o criador do Grande Vidro mistificador. E as narrativas deles?

\section{Narrativa}

O florescimento de escritos exegéticos que tratam do Grande Vidro constitui uma narrativa de proporções "épicas”. Narrativa sem fim - que nós perseguimos! -, este monumento interpretativo é inaugurado pelo meta-texto de um catálogo das notas sobre seu Grande Vidro, detalhadas e ilustradas por Duchamp, depois publicadas em 1934 com o título La Boîte Verte. Uma série de enigmas que relata a gênese do Grande Vidro e, avant la lettre, um making of. Trata-se de um work in progress. Quanto aos escritos sobre a obra dos Quay, uma bibliografia de pesquisa de obras publicadas até 2013 está acessível ${ }^{3}$. Os DVDs disponíveis de seus curtas-metragens incluem uma opção de lhes visualizar com explicações simultâneas por seus autores ${ }^{4}$; como para o DVD do Institute Benjamenta, livretos explicativos estão incluídos pela distribuidora.

Se defendendo de apoiar teorias ou propor interpretações unívocas, os Quay aceitam a sugestão de que sua arte expressa "uma subjetividade vista dentro de um sistema objetivo" (HABIB, op. cit.). Para responder à pergunta "o que contam esses artistas?", tomemos como "sistema objetivo" O Grande Vidro, esta construção épica e parcial que, como uma frase de sonho, gera a sua narrativa. Como escreveu Susan Rubin Suleiman sobre narrativas incompletas: "Seu significado reside talvez precisamente na sua capacidade de engendrar outros textos"5 (SULEIMAN, 1968).

\section{A narrativa curta}

Diferente de Freud, amante de mitos e narrativas fechadas, especialmente romances do século XIX, os Quay dizem que se preocupam pouco com "Shakespeare ou as lendas". É o desdobramento dramático clássico que, sem dúvida, os deixa indiferentes, com suas peripécias, clímax e desfecho como a resolução catártica de certos contos universais. Ao gênero "épico" do cinema mainstream, eles preferem uma forma "reduzida" ou fragmentada. Eles procedem à redução audaciosa da lenda do tirano Gilgamesh de Uruk em This Unnameable Little Broom (1985). Sendo o drama uma forma narrativa, o neologismo "dramolet", com o sufixo diminutivo em -et, refere-se ao pequeno interlúdio lírico Stille Nacht 1 (1988), bem como ao curta-metragem The Comb (1990).

3 Sobre a obra dos Quay, uma bibliografia de pesquisa detalhando os trabalhos publicados até 2013 está acessível, com resumos em alemão para as principais publicações: Wulff, Hans Jürgen: Quay Bros.: Die Filme von Stephen und Timothy Quay. Eine Arbeitsbibliographie. Westerkappeln: DerWulff.de 2013 (Medienwissenschaft: Berichte und Papiere 152). DOI: https://doi.org/10.25969/mediarep/12786.

4 Irmãos Quay. Os curta-metragens. Edição restaurada e remasterizada, Bfi ; Institute Benjamenta Channel Four Television, E.D. Distribution.

5 “La Maîtrise et le Transfert. Significations de Dora". In : Poétique XV11: Le récit à la limite. Novembre 1968, "Freud et le récit", p. 464. O autor oferece uma leitura da narrativa da análise de Freud: 0 caso Dora. Fragmento de uma análise de histeria, especialmente em seu personagem "inacabado". 
O encontro dos Quay com a prosa de Franz Kafka é fundamental. Desde sua juventude, seu Journal intime, carregado de fragmentos e de narrativas curtas e oníricas, os seduziu. Tanto que um primeiro filme adapta a narrativa kafkiana Brüdermord (Fratricida), que data de 1910-1913 e tem duas páginas e meia. Por motivos de direitos, de autor e de compositor, neste caso Kryzsztof Penderecki, este filme nunca foi distribuído. Apesar desse hiato, esse relato de Kafka contém um observador, imparcial e curioso, modelo de um personagem Quay recorrente, caminhante, voyeur, até mesmo o próprio cinematógrafo. Por fim, o dispositivo do jornal íntimo escrito pelo afinador, ouvido em voz off e iluminado com seus sonhos, estrutura a cronologia da visita do afinador à ilha de Droz.

\section{A Mulher}

O nascimento do Grande Vidro é uma saga de transmigração gradual. Inelutavelmente, a desencarnação da musa duchampiana progride. Tendo demonstrado sua capacidade para pintar nus femininos, carnudos ou esbeltos, Duchamp produziu telas que introduzem o Grande Vidro. Em 1912, Le Passage de la Vierge à la Mariée prevê as formas mecanicistas do Vidro final. Um cruzamento se produz entre as artes. A representação da mulher torna-se cinética, por meio da cronofotografia dos dois Nu descendant un escalier, 1 e 2 em 1911 e 1912 . Quanto a uma distinção sexual biológica, o Nu é ambíguo. Esta nuance de não-diferenciação é encontrada nos Quay; suas bonecas sendo bissexuais ou assexuadas; criança ou andrógino, seu personagem ignora a distância velho/jovem, como a diferença menino/menina. Tornada uma abstração no Grande Vidro, uma noiva, marionete sem sangue de maquinaria erótica, está presa em uma motricidade suspensa. Muito mais antropomórficas, as silhuetas dos nove celibatários esperam abaixo. Em vão.

Institute Benjamenta e The Piano Tuner of Earthquakes estruturam-se em torno de um objeto de desejo inacessível - a mulher -, associada a uma pesquisa artística e existencial. A frustração da tentativa abortada, seguida da retomada do mesmo esforço, pontua os curtasmetragens, como The Comb ou In Absentia, bem como o Institute Benjamenta que leva a iteração mecânica a um nível paroxístico. $\mathrm{O}$ que nos Quay não impede o retorno da tentativa idêntica. A repetitividade talvez seja para Duchamp um anátema, mas por seu título de origem, O Grande Vidro se vê em um peep-show como o cinema dos Quay com seu tema voyeurista. Autores de um documentário sobre Punch e Judy (1981), eles se lembram do parque de diversões; o Vidro remete à atração do "Chamboultou" popular, convidando o visitante a lançar bolas em um manequim, relacionado ao jogo de massacre denominado em inglês "Aunt Sally", ambos fundados sobre o gesto repetido (LEBEL, 1959, p. 33). 


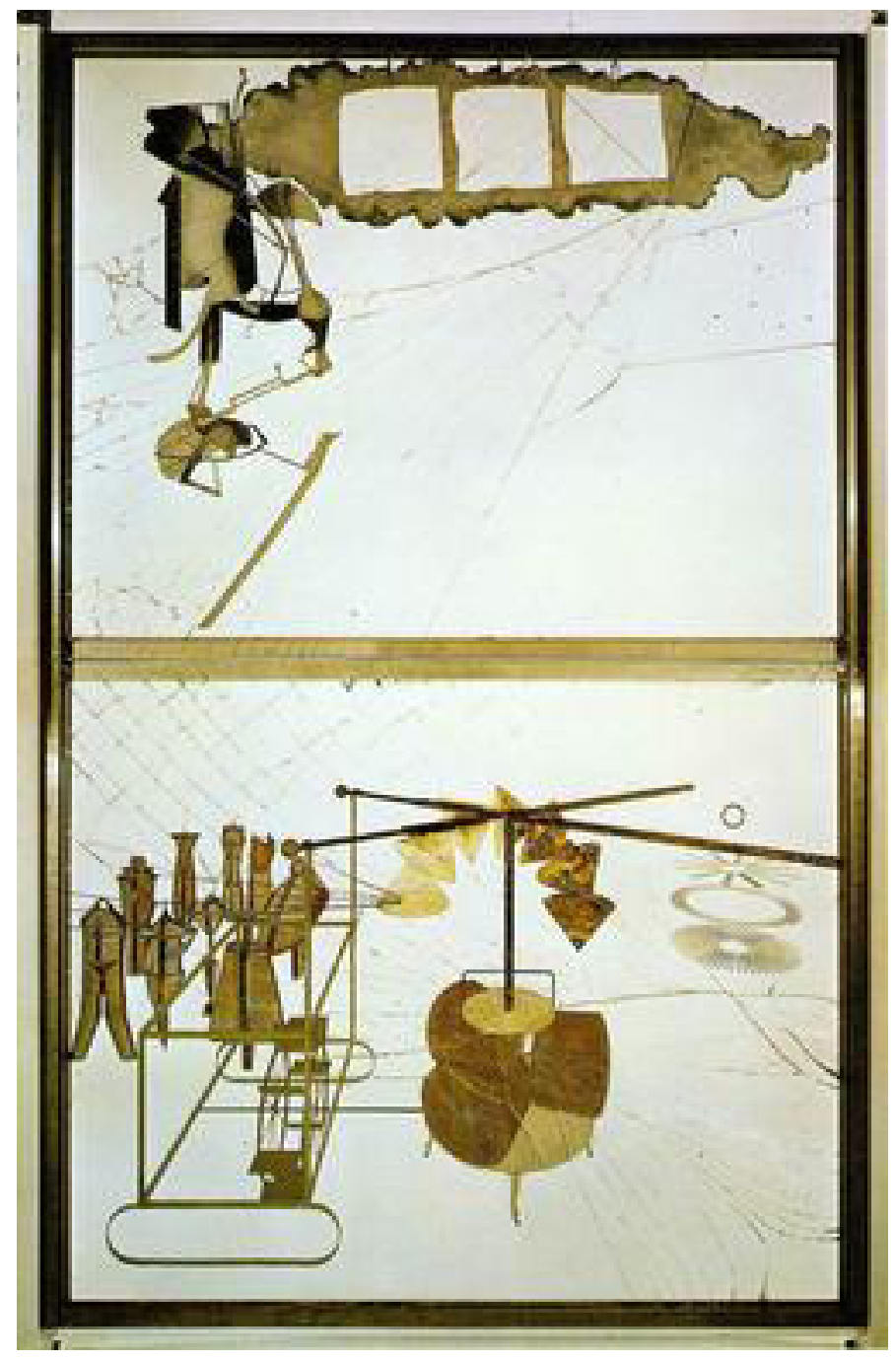

Figura 1. - Marcel Duchamp, O Grande Vidro, 1915-1923. Óleo, verniz, folha de chumbo, fio de chumbo e poeira entre painéis de vidro, 277,5 × 175,9 × 8,6 cm, Museu de Arte da Filadélfia. Fonte: wikipedia.

\section{Noiva e boneca}

E o Grande Vidro e sua narrativa? Na verdade, a obra constitui a seção inicial, senão inteira, de uma narrativa significativa. Seu título original, A Noiva despida por seus celibatários, mesmo sinaliza um fato consumado. A disponibilidade da "promessa", despida e situada no alto, é, no entanto, contradito pela posição dos moldes maliques (masculinos) abaixo. Embora ela tenha chegado "no fim do seu desejo", e apesar do princípio anunciado por Duchamp segundo o qual "Toda a importância gráfica é para este desabrochar cinemático", é esforço desperdiçado. Ela está fora de alcance. "Não há solução de continuidade entre ela e a máquina celibatária" (SANOUILLET, op. cit., p. 59). Por implicação, a figura da Noiva intocada recobre a de uma Musa declarada inoperante. A ausência de fechamento do Grande Vidro se encontra na relutância dos 
Quay em relação à completude narrativa. No entanto, onde na máquina erótica do Vidro se trata de autômatos estáticos, com um artefato indicando expressamente a parada do movimento, as bonecas Quay imaginam que são móveis! Onde elas encontram sua vitalidade?

No início é a boneca da Tchecoslováquia, berço da arte surrealista. The Cabinet of Jan Svankmajer abre sobre uma cabeça de Arcimboldo, saída do gabinete de curiosidades do Imperador Rodolfo XI em Praga e emblema do mentor dos Quay. Pequena fábula encantadora, é encenada entre um mestre e um(a) aluno(a) que se familiariza com as ferramentas da fabricação ilusionista, os bonecos com crânios perfurados, uma escada com a qual escalamos para o que está fora de alcance, e a trilha sonora. Com suas ferramentas de base, os Quay reinventam à sua maneira um gabinete de curiosidades.

Entretanto, o polonês transgressor Walerian Borowczyk, artista ilustrador como os gêmeos, que assina Renaissance em stop-motion (1964) e Contes Immoraux (1984), está mais próximo deles, exploradores de uma veia decadente. No voluptuoso conto que é The Piano Tuner of Earthquakes, um close-up da laringe de Malvina remete à vulva da vagina. O homoerotismo contido nas paredes do Institute Benjamenta é mais pronunciado na ilha ameaçada por uma catástrofe da natureza.

\section{Recitação}

A falta de comunicação das bonecas mudas do stop-motion se repercute nos monólogos, refrãos e textos impressos e legíveis do Institute Benjamenta. Abre com uma voz em off recitando em alemão uma série de adágios paradoxais do gênero; aquele que ousa não tem coragem. Visto que os atores de carne e osso, subjugados por sua professora Lisa, declamam e recitam de cor as ladainhas, como as litanias representadas pela lâmina do Grande Vidro. 0 quadro-negro da sala de aula está coberto de adágios que os aprendizes entoam. Emoldurado e adornando os quartos, o bordado vitoriano promulga antiquados provérbios de uma banalidade que só pode estimular o desejo de progresso ou mudança.

\section{Narrativa e Cinematografia}

Se a cantora Malvina se faz ouvir pela música, as outras criaturas dos Quay são quase tão silenciosas quanto a Noiva de Duchamp. A narrativa Quay avança, em três pontos notáveis próximos da visão estética de um de seus cineastas admirados, Robert Bresson (BUCHAN, 2011, p.135). Para eles, preocupados com a atividade da mente, a eloquência da imagem visual e da trilha sonora prevalece sobre o diálogo e sobre a ação corporal. Em maiúsculas, lemos a máxima bressonniana: O CINEMATÓGRAFO É UMA ESCRITA COM IMAGENS E SONS EM MOVIMENTO E SONS (Bresson, 1975, p.18). O cineasta esclarece: “É preciso que os ruídos se tornem música” (id, p.32.). Música, imagem e gestos: a tríade dos Quay já foi decretada. Bresson rejeita a narrativa do cinema convencional como sendo teatral e fotográfica. Ele aplica à arte cinematográfica a palavra "cinematógrafo", que designa originalmente a máquina ótica. Com ele se esboça a nostalgia de um passado que sustenta a arte sutil dos animadores. As bonecas datam da infância, mas também da condição pré-verbal das crianças. Veiculado por suas folhas empilhadas e cobertas de um grafismo ilegível, o limite da mudez torna-se a loucura da paciente Hauck. 
Nocturna Artificialia, a narrativa noturna de um caminhante solitário, é pontuada por uma mini narrativa composta por oito intertítulos surrealistas em inglês, polonês, alemão e francês que, além de inacabados, confirmam o que a imagem transmite. Recitada na primeira pessoa, a ação se resume como segue: "Na sombra da noite, em um movimento mecânico, um homem solitário sai para a rua, espera e vê um bonde elétrico vermelho com poste que passa sob uma catedral, momento no qual ele experimenta “uma êxtase inefável'”.

Neste momento, o rosto de uma bela Virgem bizantina preenche o campo até a borda e nos fixa o olhar. Sobreposta à sua face, aparece uma escala, objeto que retorna em Street of Crocodiles e em The Comb. Uma música stringendo alterna com a ressonância elétrica e acordes de órgão. Conta-se uma interioridade do vivido, transmitida pela música, uma tentativa de tecer uma ligação entre a experiência sepultada e o exterior, entre o hoje e ontem. É a matriz poética da narrativa dos Irmãos.

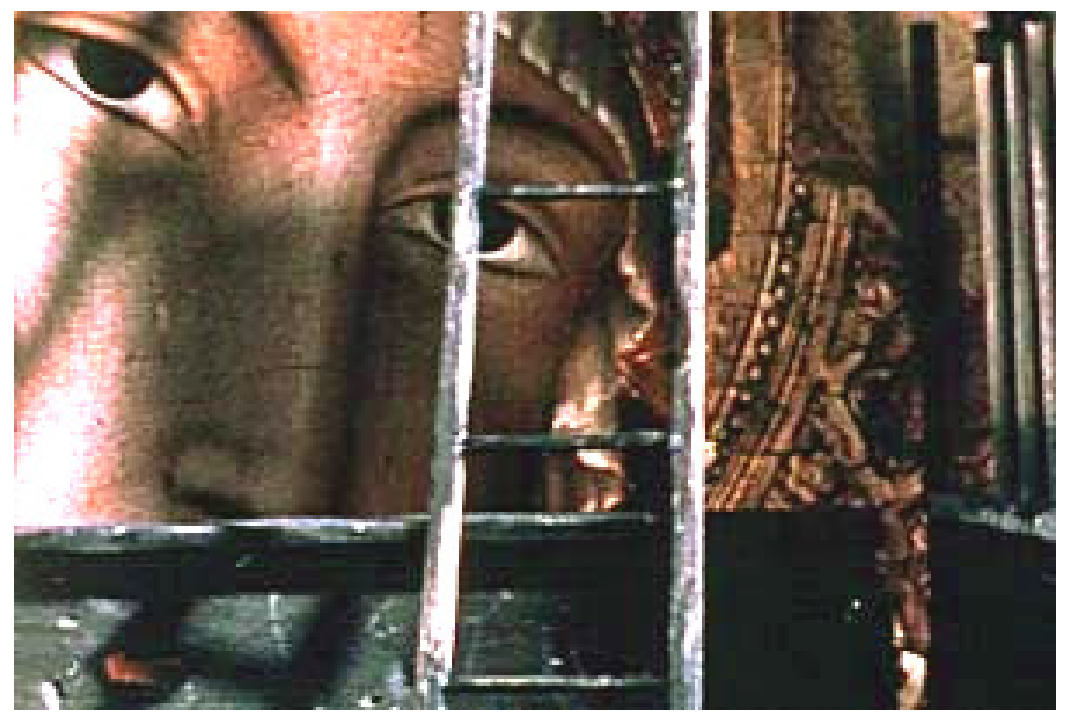

Figura 2. - Irmãos Quay, Nocturna Artificialia, 1979, 21 min., British Film Institute Production Board. Fonte: imagem da autora 6

Composto de sete aprendizes, descendentes dos sete anões de Branca de Neve (O’NEILL, 200 0, p. 26-27) e acompanhado pelo Diretor e seu assistente Kraus, o conjunto de nove homens do Institute Benjamenta corresponde ao grupo de nove moldes maliques, os celibatários do Grande Vidro. No Institute Benjamenta, a existência dos alunos gira em torno de uma única mulher presente, aqui, Lisa. A narrativa das últimas semanas daquela que será enterrada com um vestido de noiva deslumbrante está impregnada de uma triste ironia pois, com a chegada de Jakob, não há nada

6 Todas as três fotos tiradas dos filmes foram publicadas com permissão dos Irmãos Quay. 0 autor e os editores expressam seus sinceros agradecimentos. 
de novo para contar. 0 interesse do conto e do filme consiste em recitar-nos precisamente esta gafe ${ }^{7}$. Esta paródia fustigante do romance de aprendizagem é uma metáfora da vida, declinando humilhação, beleza, sensualidade e a iniciação ao nada. Para se impregnar da verdade afixada na parede do Instituto: “As Regras já pensaram em tudo”.

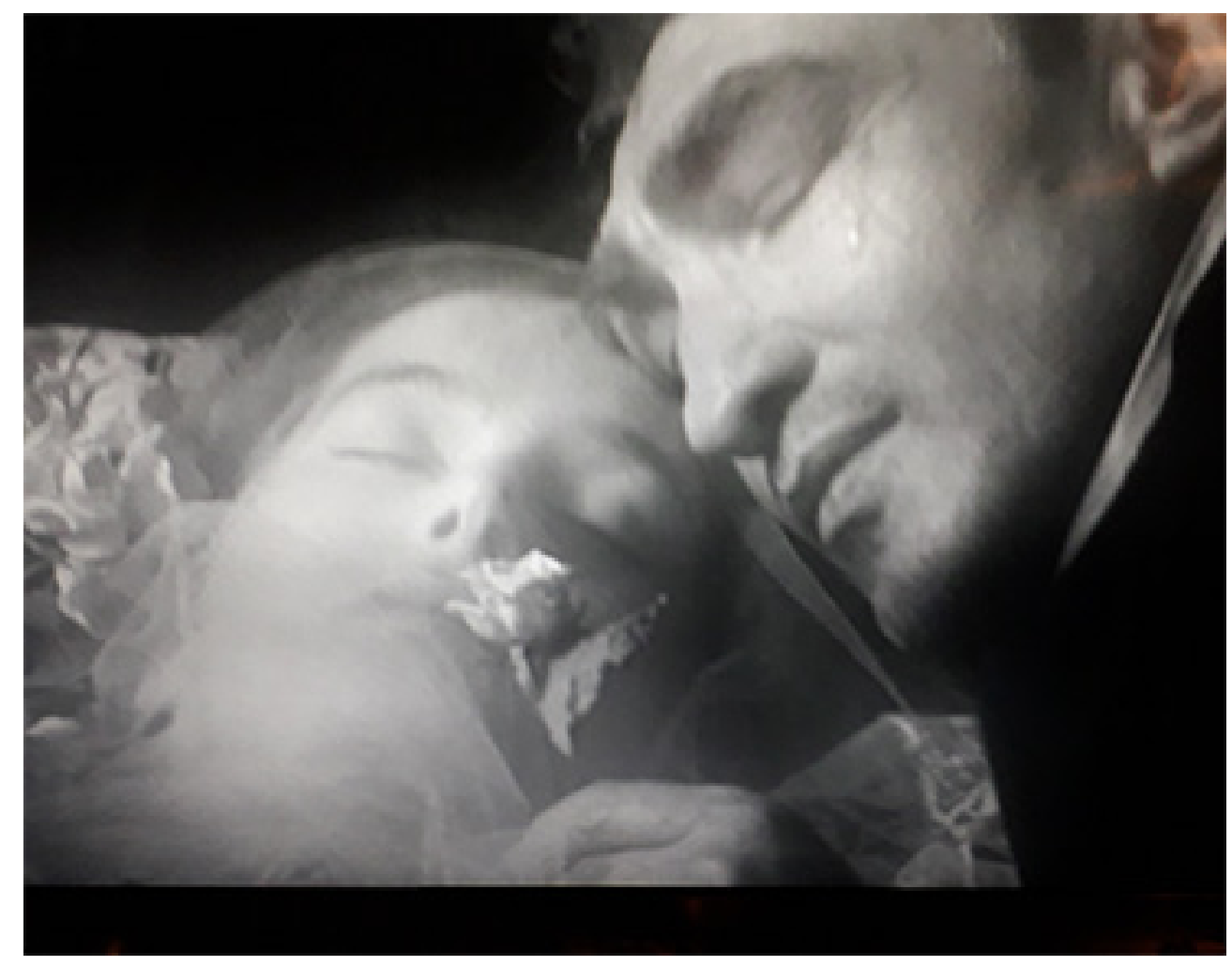

Figura 3. - Irmãos Quay, A Morte de Lisa, Irmão e Irmã no Institute Benjamenta, 1995, 1h45min.

Fonte: foto da autora.

A narrativa Quay é uma autocitação perpétua. A tropa de aprendizes reduzida ao estado de autômatos retorna nos empregados do neurologista Droz em The Piano Tuner of Earthquakes. Seu castelo é uma réplica de "A Ilha dos Mortos”, de Arnold Böcklin (1880). Além disso, a narrativa Quay releva o contato com a arte representacional, aqui em uma figura simbolista e decadente, uma citação e recitação de nossos últimos fins. Para se proteger contra o estrondo da terra, este louco contrata Felisberto, afinador de pianos. Ele se pergunta em voz alta: Eu penetrei em um quadro já pintado? Com efeito, o convidado repete a narrativa de base da ficção tentando salvar a cantora de uma inverossímil

7 Aux confins du récit, sob a direção de Bruno Clément e Clemens-Carl Härle, Presses Universitaires de Vincennes. Philippe Lacoue-Labarthe é citado na introdução: “Uma narrativa não pode terminar sem ter tido um começo - sendo que retorna para o mesmo, desde um longo tempo completado". E Jean-Luc Nancy escreve: "A narrativa volta ... Com a narrativa... abraçamos a distensão do sempre-já e do jamais-ainda, o suspense do evento. p.26, "Narrativa, recitação, recitativo". 
segunda morte. Assim, tentamos re-recitar a trama que se enrola sobre ela própria. Declinando o entrelaçamento de Eros e Thanatos, a narrativa dos Quay conta o eterno retorno do mesmo. Para o criador do Grande Vidro, uma tal narrativa seria anacrônica: o que era não será mais.

No fundo, The Piano Tuner of Earthquakes contém uma composição musical que reforça a referência na homenagem a La Jetée de Chris Marker (1962). O célebre curta-metragem de antecipação evoca a perda sofrida por um menino que se lembra do rosto de uma mulher visto pouco antes da destruição de Paris. Descoberta por acaso, esta partitura, destinada a um balé que "nunca aconteceu" e com o título tristemente apropriado de The Unwanted, foi escrita para a editora musical Boosey \& Hawkes e restaurada para os Quay. Se o afinador Felisberto e a cantora estão unidos, é durante uma tempestade e entre as rochas. A cena final permanece a completar, a grande narrativa persiste. Pois se trata no fundo nos Quay da busca do desejo.

\section{Street of Crocodiles}

Um erotismo fetichista e lúdico pelo tema de sapatos de salto alto é delineado na ilha do doutor Droz e na Street of Crocodiles. Novamente, um senhor careca sai às ruas de um bairro dilapidado com lojas antiquadas onde os sapatos de salto alto aparecem como sinal de impulso sexual e de promessa. Narrativa de um passeio que capta pela imagem, pelos gestos e pelos sons uma expressão intensa de retorno impossível, possui uma sensibilidade, para dizer a verdade, inenarrável. Aqui um trecho:

Nós sempre teremos o arrependimento de outrora ter deixado esta loja de roupas equívoca. Nunca mais nós poderemos reencontrá-la. Iremos vagar de um ensinamento para outro, nos enganando sempre. Visitaremos dezenas de lojas bastante semelhantes, caminharemos entre muralhas de livros, folhearemos publicações, teremos conversas confusas com vendedoras com a pele excessivamente pigmentada e à louca beleza que nada entenderão de nossos desejos (Schulz, 1974).

Da mesma forma que o Institute Benjamenta e a ilha de Droz se desintegram e desaparecem, Street of Crocodiles e seus edifícios desmoronam diante de nossos olhos e voltam a ser pó. Após suas andanças em Street of Crocodiles, o stalker retorna de mãos vazias. Se ele não descobre nada do que esperou, é como se ele encontrasse a Noiva despida sem que nada se passe? Uma narrativa, é sempre o que já foi? Como uma narrativa de sonho? Kafka escreveu: "O talento que tenho para descrever minha vida interior, essa vida que parece um sonho.... Observe que ele usa o termo Darstellung (representação) para incluir a plena nuance gráfica. Ele e os Quay: almas gêmeas? 8

8 Kafka: Jornal intimo, 06 de agosto de 1914 "Der Sinn für die Darstellung meines traumhaften inneren Lebens ..." : "O talento que tenho para descrever minha vida interior, essa vida que parece um sonho...", Livre de Poche pour les Éditions Grasset, 1954, p. 385. Traduzido por Marthe Robert, tradutora de Jakob von Gunten que the deu o título Institute Benjamenta. 


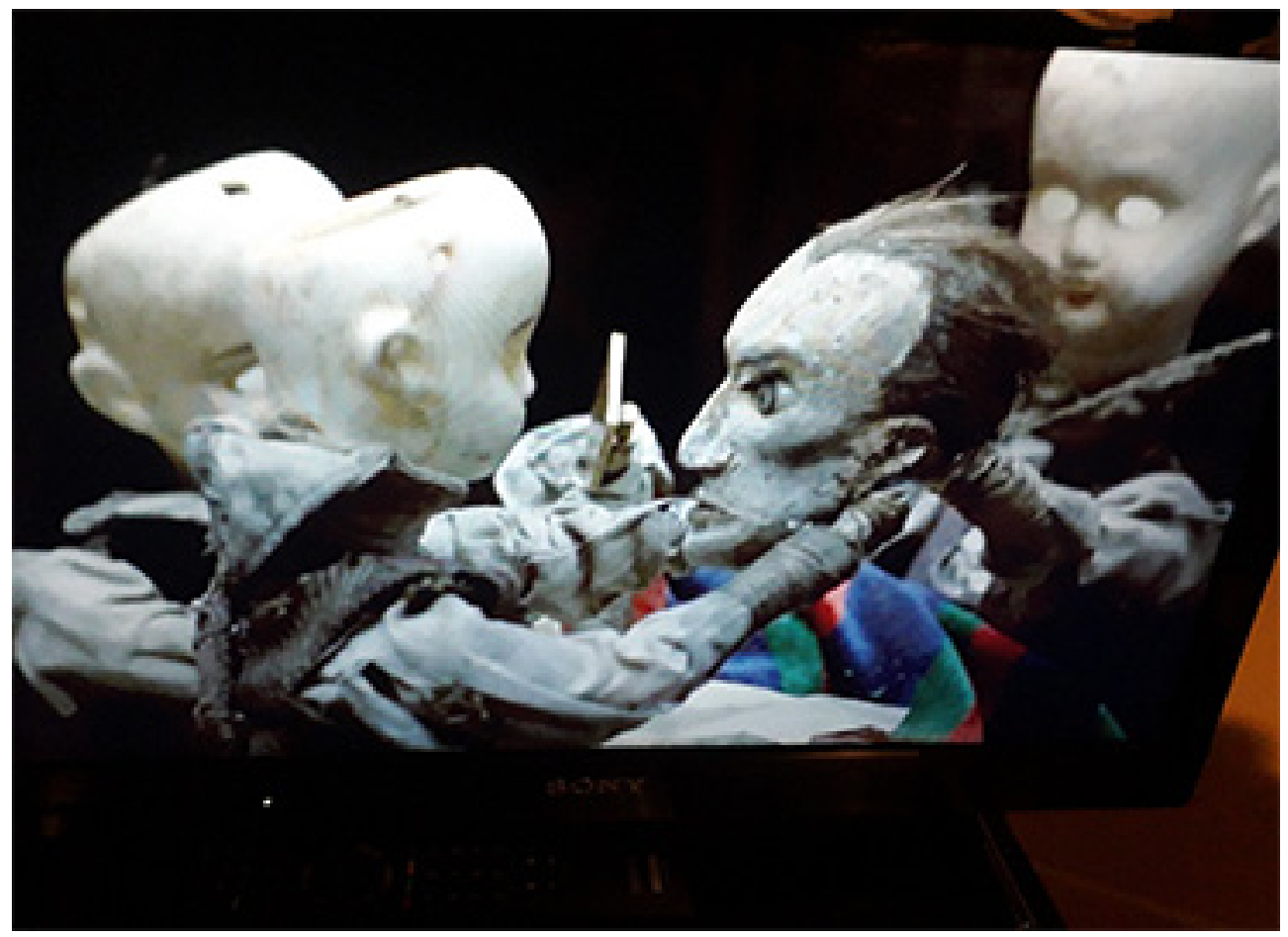

Figura 4. - Irmãos Quay, Street of crocodiles, 1986, Curta-metragem de animação, 20min.

Fonte: foto da autora.

Após o cataclismo da Segunda Guerra Mundial e depois do Vietnã, os Irmãos americanos se exilam na Europa. Ao filmar Street of Crocodiles, eles pesquisam o bairro judeu de Cracóvia. Aqui é feita uma homenagem à Polônia, como eles dizem, "cortada pela sua história". Segundo seus criadores, o talhador mexendo com fatias de carne fresca sobre as partes genitais do visitante é um megalomaníaco como aqueles que teriam participado das "carnificinas" das quais a região foi vítima. Por mais onírica que seja, a narrativa Quay se insere na Grande História.

\section{Conclusão}

Esse sonho que chamamos vida humana: o título anexado ao Institute Benjamenta transpõe as palavras de Jakob na narrativa de Walser: "toda minha estadia neste lugar me parece um sonho incompreensível" (GUNTEN, 2017, p.10). The Comb tem o subtítulo: From The Museums Of Sleep. Os Quay fazem-nos entrar neste reino como em um sonho, como Kafka que diz que o seu tema nada mais é do que a sua vida onírica, para ele "a única vida que importa..." O Grande Vidro não é a representação de uma noiva, mas a apresentação de uma ideia. Ela equivale a uma ficção mental, ou figura "onírica", logo, é um fantasma e sinônimo de um desejo indiretamente articulado. Por definição, fantasmático é a qualidade que Duchamp visa substituindo aos traços "realistas” índices hieroglíficos. 0 que não impede que essa ideia seja seu fantasma também. 


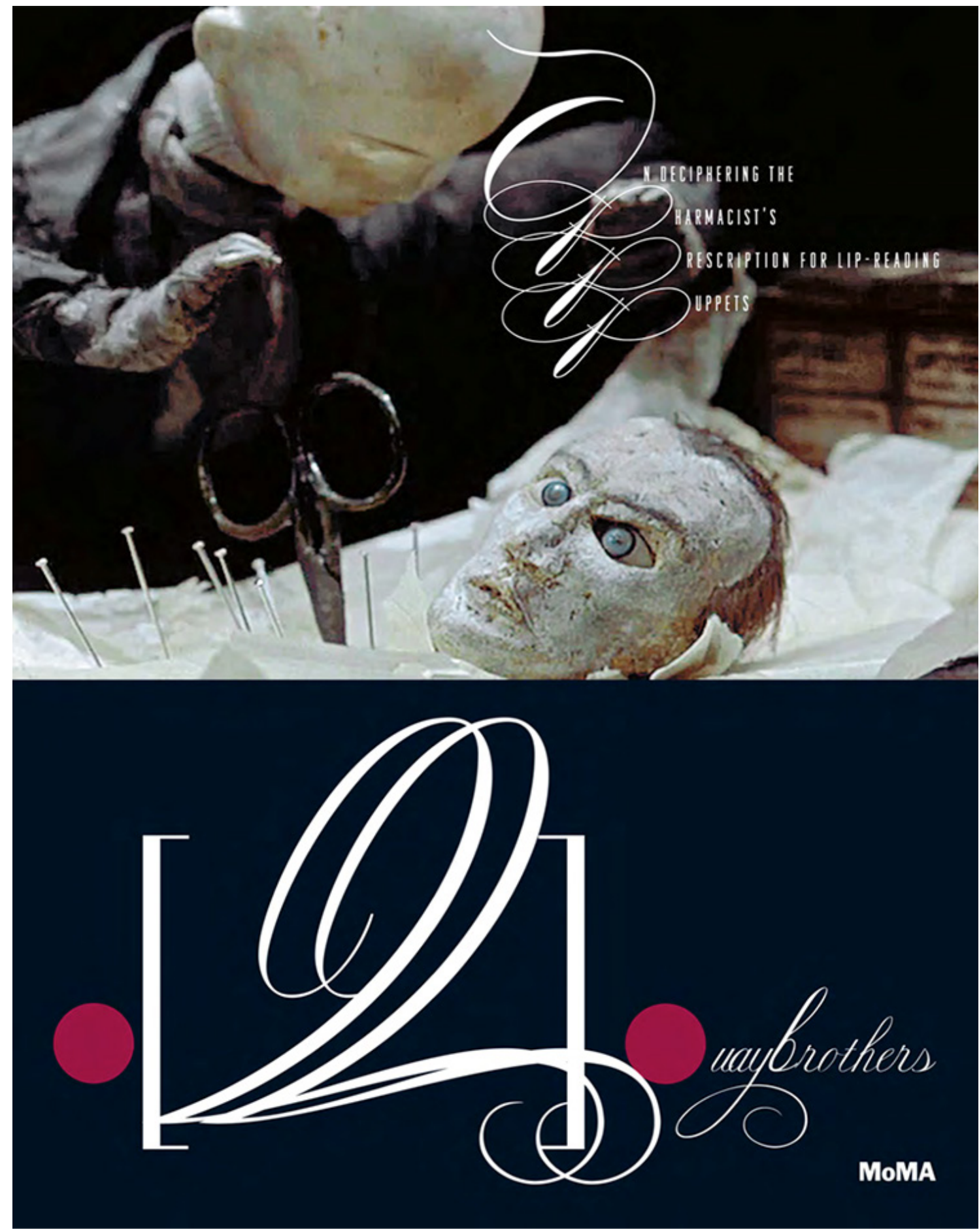

Figura 5. - Exposição Quay Brothers: On Deciphering the Pharmacist's Prescription for Lip-Reading Puppets, MOMA, 2012. Source: https://www.moma.org/calendar/exhibitions/1223 


\section{Desejo}

Da mesma maneira que para Kafka, para os Quay, descrever seus sonhos é uma questão de desejo vital. Nocturna Artificialia é dedicada "para aqueles que desejam sem fim" (To those who desire endless(y). Se tratando de desejo, a Noiva do Grande Vidro tem uma palavra a dizer. Descrevendo em La Boîte Verte a máquina celibatária, o artista indica que a última parte dela consiste em uma máquina do desejo "separada (da Noiva) por um refrigerador com aletas... e (que) a Noiva recusa calorosamente... a oferta repentina dos celibatários". Ignorando o aspecto cômico da fábula duchampiana, e ignorando o destino da Noiva, é razoável deduzir que por essa "apoteose da virgindade" segundo a fórmula de Duchamp, o desejo permanece intacto. Introduzido pelo oximoro quente/frio, o desejo em suspensão está bem em seu lugar. É certo que o observador do Grande Vidro possa ver ali os signos remetendo um tempo parado, a uma narrativa que se difere, daí a necessidade de recomeçar. No entanto, quando os Quay se dirigem para aqueles que desejam "sem fim", é algo de inominável que escapa eternamente.

Ora, toda coisa nomeável tem um fim. A narrativa Quay o mostra, através do declínio de Impérios e de ilhas, da passagem de vida à morte de Lisa e de Malvina. Street of Crocodiles é um filme evocador do gueto e do Holocausto. Jakob e o Diretor sobreviverão à tempestade de neve na qual eles mergulham? Malvina é uma aparição ou ressuscitou? Ela perecerá nas vagas? Mulher sonhada? Nesse caso, tudo é ilusão. Sem ofender aos Quay, é a Barda que escreve "Somos feitos de estofo dos sonhos" (La Tempête, Ato 1V, cena 1). Ninguém discordou. Todavia, a epígrafe escolhida para The Piano Tuner of Earthquakes é um extrato do Capítulo 4 do Tratado dos Deuses e o Mundo do romano Salústio. O historiador e filósofo escrevendo sobre fábulas fantásticas declara: "Não é que essas coisas nunca tenham ocorrido, mas que elas existiram o tempo todo". Isso expressa um pensamento que ultrapassa o elemento episódico de nossas narrativas. É a permanência do universo que é invocada; a incorruptibilidade é sua garantia. E acrescenta Salústio: "a corrupção de uma coisa é sempre a geração de uma outra - que propriamente é apenas uma transformação". Esta fé que motiva o Doutor rejeitando a morte de Malvina sustenta os Quay que procedem à transmigração das formas. Eles não fazem surgir porcas de poeira da Street of Crocodiles como em tantos versos ou flores primaveris?

\section{Poeira da vida}

Por excelência símbolo da mortalidade humana, a poeira é preservada pelos Quay, nisso seguindo Duchamp. The Comb - tão ready-made quanto Le Peigne de Duchamp (1916) -, abre-se com um close-up de um pacote embalado e amarrado em cujo rótulo se lê: PULVIS PUMICIS SUBTILISS (sic). Esse Pó fino de pedra-pomes, uma poeira de pedra vulcânica, se encontra sobre uma penteadeira. Este filme sobre uma mulher adormecida é rodado em ótica anamórfica e constitui um prelúdio do Institute Benjamenta. A abertura cinza e granulada, como vista através de um véu de poeira, rapidamente dá lugar a cenas de paisagens abertas em cores outonais e quentes. Um subtítulo: “Na borda da floresta... perto do outono". Ao longe, uma escada. Uma boneca a agarra, mas: "De repente o ar se endurece", e a boneca se desmantela. No violoncelo, uma música elegíaca. A boneca ganha vida e se levanta para se engajar em uma tentativa de 
ganhar ar, escadas ajudando. Dois ramos verdes crescem, a mulher acorda de seu sono agitado, retornamos para a penteadeira e o pacote fechado e ela se penteia. Sonho de mulher ou sonho em torno da mulher? O filme parece uma narrativa de morte e ressurreição. Memento mori, mas também uma garantia de renovação. "Não há matéria morta. A ausência de vida é apenas um disfarce sob o qual se escondem outras formas de vida" (Bruno Schulz). O pacote, nunca aberto, perpetua a poeira. Ela está aí, sob uma forma refinada que faz jus à narrativa Quay, assim como ao edifício de vidro de seu antecessor. Em um mundo de incertezas, a mulher, "um reservatório da essência do amor", diz Duchamp, é submetida, mas não mais do que o homem. Desafiando o tempo, cada um se entrega à sua solidão, à narrativa de sua própria interioridade, única e poética. 


\section{Referências}

BRESSON, R. Notes sur le cinématographe (1975), Gallimard, 1975, avec préface de J. M. Le Clézio, Folio, 1988.

BUCHAN, S. The Quay Brothers. Into a Metaphysical Playroom, University of Minnesota Press, 2011. https://doi.org/10.5749/minnesota/9780816646586.001.0001

HABIB, A. "Through a Glass Darkly - Interview with the Quay Brothers », 2002, dans www. sensesofcinema.com/2002/feature-articles/quay/through a glass darkly »; La version en français de cette entretien est publiée dans la revue Hors Champ, disponible dans www.horschamp.qc.ca/ cinema/jan2002/quay.html, consulté le 12/02/2021.

LEBEL, R. Marcel Duchamp, Belfond, Paris, 1985.

LEBEL, R. Marcel Duchamp, Paragraphic Books, New York,1959.

O’NEILL, Eithne. “La Mort de Blanche Neige”, Positif, n 471, mai, 2000.

ROSE, J. Where the dust has settled: The Brothers Quay, em: www.sensesofcinema.com/2004/ great-directors/quaybrothers/Issue; Acesso em 05/12/2020 (Trad. Eithne O' Neill).

SANOUILLET, M. Duchamp du signe. Écrits, avec la collaboration de Elmer Peterson, Flammarion, Paris, 1975.

ROUSSEL, R. Locus Solus, Jean-Jacques Pauvert Éditeur, 1965.

SULEIMAN, S. R. La Maîtrise et le Transfert. Significations de Dora. In: Poétique XV11 : Le récit à la limite. Novembre, 1968.

SCHULZ, B. Les Boutiques de cannelle ou La Visitation (Traduction Georges Sidre), Étrangère, Gallimard, 1992, après Éditions Denoël 1974.

WALSER, R. Jakob von Gunter, Journal intime, Suhrkamp Verlag, Taschenbuch, 2017. 


\section{Sobre a autora}

Eithne O'Neill é escritora, crítica de cinema; membro do SPAF (Syndicat de la Presse Artistique Française). Nascida e educada: Dublin, Munique, Tubingen, Paris. Vive em Paris. Livros: Stephen Frears, Rivages, 1994; Le Voyage de Chihiro, Vendémiaire, 2019; Lubitsch: La Satire Romanesque, com J-L. Bourget, Stock 1987. Chemins faisant. Poèmes, Elzévir, 2010. Comitê editorial: Positif (1996-). A ser lançado em 2021: Esclavage moderne à l'écran; La Nostalgie chez Bertrand Tavernier; La Femme selon Robert Siodmak. Atividades: Juri Syndicat Français de la Critique de Cinéma (S.F.C.C.): Cinéma Amérique Latine, Toulouse, Biarritz., Arras, Villerupt, Lille. Juri FIPRESCl: Cracóvia, Vienna, Jérusalem, Turim, Luxembourgo, Karlovy Vary, Ljubljana, Mannheim, Rotterdam, Frankfurt - Wiesbaden; Berlim. Festival de Filme, São Paulo, 2012. Juri Literária e DVD Blu-ray. S.F.C.C.: 2013-2016: Club Gaélophone Paris.

ORCID: https://orcid.org/0000-0002-2596-0927

\section{Sobre o tradutor}

Fabio Fonseca é docente do curso de Artes Visuais da Universidade Federal de Uberlândia (UFU), na subárea de Desenho. Doutor em Teoria e Históriada Arte pela Universidade de Brasília (UnB), com período sanduíche no Centro de Linguística da Universidade de Lisboa. Mestre em Teoria e História da Arte pela UnB. Especialista em História da Arte do Século XX e Bacharel em Gravura pela Escola de Música e Belas Artes do Paraná (EMBAP-PR). Atualmente desenvolve sua pesquisa sobre o processo de sobrevivência das imagens, procurando integrar sob um viés teórico-metodológico, a pesquisa em Teoria e História da Arte com a produção prática em Artes.

LATTES: http://lattes.cnpq.br/4450453554832020

ORCID: https://orcid.org/0000-0002-1371-5502

Recebido em: 23-05-2021

\section{Como citar}

O’NEILL, Eithne ; FONSECA, Fábio. (2021). A Arte dos Irmãos Quay à luz do Grande Vidro: a Narrativa. Revista Estado da Arte, Uberlândia. v.2, n.1, p. 249-265, jan./jun. 2021. https://doi.10.14393/EdA-v2-n1-2021-61248 